\title{
Effect of Information and Communication Technology Tools for Instructional Delivery in Tertiary Institution in Nigeria
}

\author{
Ezemoyih Chuks Marcel ${ }^{1}$, Okike O. Celestine ${ }^{2}$,Kingsley S.U. Oyekezie ${ }^{3}$, Beatrice Eze ${ }^{4}$
}

\section{ARTICLE INFO}

Article History:

Received 11.11.2019

Received in revised form

05.09.2020

Accepted

Available online 01.10 .2020

\begin{abstract}
One of UNESCO's overriding aim is to ensure that all tertiary institutions both colleges of education/polytechnics, and universities have access to the best of educational facilities necessary to prepare young people to play full roles in modern society and to contribute to a knowledge nation. They maintain a capacity to advise national government on the use of technology in schools and in particular on the use of institutional delivery tools. It defines ICTS, classified four basic institutional uses of such as retrieval of new knowledge and integration of evolving technologies for the management of teaching and learning. E-learning, blended learning, open and distance learning, learner centered environment as well as to improve quality of education were highlighted challenges confronting institutional delivery were examined. Recommendations were made which include the parliamentarian should pass a bill on stabilizing the price of educational tools in the markets to make it affordable for students to acquire at a reduced rate. Also conferences, workshops and symposium should be organized to train people and enlighten them on the need for instructional delivery in schools.
\end{abstract}

(C) IJERE. All rights reserved

Keywords:

Information, communication, technology, instructional delivery and tertiary institution.

\section{INTRODUCTION}

Information and communication technology (ICT) is a force that has changed many aspects of the way we live. If one was to compare such as medicine, tourism, travel, business, law, banking, engineering and architecture, the impact of ICT across the past two or three decades has been enormous (Nzeako, Iwu and Anacle 2012). According to them, the way these fields operated today is vastly different from the ways they operated in the past. But when one looks at education, there seems to have been an uncanny lack of influence and far less change than other fields have experienced. A number of people have attempted to explore this lack of activities and influence but failed. Conventional teaching has emphases context. For many years course have write around textbooks. Teachers have taught lectures and presentations interspersed with tutorials and learning activities designed to consolidate and rehearse the content. Contemporary settings are now favoring curricula that promote competency and performance-based curricular are well supported and encouraged, by emerging instructional technologies( Collins 2002), such curricular tend to require access to a Variety of information sources, access to variety of information forms and types; student centered learning settings, based on information access inquiring learning environment centered on problem centered and enquiry based activities, authentic settings and examples and teachers as coaches and mentors rather than context experts (Oliver 2000). In recent years there has been a groundswell of interest on computers and the internet can best be harnessed to improve the efficiency of education at all levels and in both formal and non-formal settings (Iwu 2012) But information and communication technology (ICT) is more than just these technologies (Nzeako 2012), Older technologies such as telephones, radio, and television, although now is given less attention, have a longer and richer history as instructional tools. For instance, radio and television have for over forty years been used for open and distance learning, although print remains the cheapest most accessible and therefore most dominant delivery mechanism in tertiary institutions. The use of instructional delivery tools is still I its infancy in our tertiary institutions. Moreover, different technologies are typically used in combination rather than as the sole delivery mechanism.

\section{What is instructional delivery tool}

Instructional delivery tool is a planning tool for developing an integrative service delivery plan that focuses on giving students who show least and most instruction and related service support. Instructional delivery tools (Nzeako, Iwu and Anaele 2013), are diverse set of technological tools and resources used to

\footnotetext{
ezemoyihchuks1961@gmail.com, orcid.org/0000-0002-9298-1322.Department Of Vocational And Technical Education, Alex Ekwueme Federal University Ndufu Alike Ikwo Ebonyi State 2 okikeus@yahoo.com, orcid.org/0000-0002-0681-1352, Alvan Ikoku Federal College Of Education Owerri Imo State

3 orcid.org/ 0000-0002-4631-6724.Alex Ekwueme Federal University Ndufu Alike Ikwo Abakiliki Ebonyi State.

4 aebeatrice@gmail.com, orcid.org/0000-0001-9350-3755, Alex Ekwueme Federal University Ndufu Alike Ikwo Abakiliki Ebonyi State
} 
communicate, internet, create disseminate, store and facilitate sharing of information and provide educational opportunities in a rural community. Instructional delivery tools are tools that has an input, output and we must be able to process with it (Baron, 1998) To support these opportunities, instructional tools can support these opportunities, instructional uses namely, retrivieval resource, and integration of evolving technologies for the management of teaching and learning.

Harris (1998) identified tools for retrieving information as;

A (i) Computer.

Information exchange about cultural traditions, environmental issues, promising practices, expert consultation online, and tile field tropism information providers, when access to digital libraries of information, photos, documents and databases, common documents, such as collected stories that are published electronically, news analysis in electronic magazines.

(ii) Video

Information, satellite delivered programming images in the form of slides, films or video tapes.

(iii) Audio

Radio access to information and stories.

Nwosu 2017 also identified some some tools for communication as follows:

B (i) Computer.

E-mail exchange involving interaction between students, teachers, adults, and exports in a global learning environment, news groups, forums and internet bulletin boards where common topics of interest explored distance mentoring in which universities, business and schools provide online services in the form of mentoring and integrated learning packages and courses, real time, text based interactions.

B (ii) Video

Live, interacting video and video conferencing opportunities between two or multiple sites provided by real time video capability combined with audio tools.

B (iii) Audio

Interacting technologies using the telephone, audio conferencing and radio wares.

B (iv) Print

Print still considered viable tools for study guides, course syllabic, case studies, support text and so on.

Tools For Electronic/Multimedia, Production and presentation.

C(i) Video

Image/Sound Capturing, editing and production devices, assessment, profiles and data bases.

$C$ (ii) $C D$

Mixed media presentation for web publication.

D Integrated mixture of tools that support instructional management.

$D$ (i) Online.

For Management of Resources, Assessment, Profile and Databases

Littlejohn (2012) asserted that a variety of mixed media is commonly used. It might include a print component in the form of course text, reading, schedules or syllabi accessed through the internet. Two ways interactive audio or video can provide real time face to face and voice-to-voice interaction. Live audio/video media can incorporate guest speakers, mentors and content experts who would otherwise not have the opportunity to be in class. Communication among teachers, mentors and peers can be accomplished through computer conferencing, electronic mail and online forums. Pre recorded video tapes can be used for class presentations, distribution of assignments and announcement can be transmitted via Fax. Collaborative problem solving among global partners project can be conducted using current delivery media.

Diffy, \& Euningham(2006) highlighted more instructional tools such as;

E learning: Most commonly associated with higher education and corporate training, 
E-learning encompasses learning at all levels, both formal and non formal that uses an information network, the internet, (LAN) or extract (WAN) whether wholly or in parts for course delivery, interaction, evaluation and facilitation, others prefer the term on line learning.

Web based Learning: Blended learning refers to learning models that combine traditional class Room practice with e-learning solutions. Blending was prompted by the recognition that not all learning is best achieved in an electrically mediated environment particularly one that dispenses with a live instructor altogether. Instead, Consideration must be given to the subject matter, the learning context in under to arrive at the optimum mix of instructional and delivery methods: Open and open and distance learning is defined by common wealth of learning as 'a distance way of providing opportunities that is characterized by the separation of Learning teacher and leaner in time or place or both time and place, learning is certified in some way by an institution or agency, the use of a variety media, including print and electronic two ways communications to allows learners and tutors to interact the possibility of accessional face to-face meetings and a specialized division of labor in the prediction and delivery of courses.

Learner Centred: The national research council of the US defines learners. Centered environments as those that pay careful attention to the learners bring with them to the classroom. The impetus for learner centered devices from a Theory of learning called constructivison which views learning as a Process in which individuals 'Construct' meaning based on poor knowledge and experience. Experience enables individuals to be Mental model schemes, which in turn provide meaning and Organization to subsequent experience. A form of constructivision called sound construction also emphasizes the role of the teacher,Parents, peers and other community members in sapling learners to master couples that they would be able to industry on their own for social constructions, learning must be active contextual and social. It Is done in a facilitor or guide.

Collaborativ E learning: Information and communication technology supported learning courages Interaction and co- operation among students, teachers and experts Regardless of where they are. Apart from modeling real world interaction,Information and communication technology supported learning provides learners the opportunity to work with from different cultures, thereby helping to enhance learners, teaching lifetime by expanding the learning space to include not just peers different field Online. Online learning involving students logging in to formal courses. Online is Perhaps the most commonly throughout application of the internet in Education.

Web based collaboraive tools: web-based collaboration tools, such as e-mail list severs, message boards, real time chat and web based conferencing connect learners to other learner $S$, teachers, educations, scholars and researchers, scientists, industry leaders and politicians to any individual with access to the internet who can enrich The learning process.

Telecollaboraion: The organized of web resources and collaboration tools for curriculum appropriate purpose is called telecollaboration. Harris (1998) defines telecollaboration as an educational endeavour that involves people in different locations using internet tools and resources to work together. Much educational collaboration is curriculum based, teacher designed and teacher coordinated. Most use e-mail help participants communicate with each other. Many telecollaborative activities and projects empower student To become active, collaborative learners.

Radio and Television: radio and television have been used widely as educational tools since 1920s 1950s respectively, three general approaches to the use of radio and Television broadcasting in education include direct class teaching, where Broadcasting programs substitute for teachers on a temporary basis, Secondly school broadcasting, where broadcasting programs provides complementary teaching and learning resources not otherwise available, Thirdly, general educational programming over communities, national and International nations which provide general and informal educational opportunities. The notable and best documented example of the direct Class teaching approach in interactive radio instruction (IBI). This consist of ready made 20-30 minutes direct teaching and learning exercise to the classroom on a daily basis.

Teleconferencing: Teleconferencing refers to interactive electronic communication among People located at two or more different polices. There are four types of Teleconferencing based on the nature and 
extent of interactivity and the sophistication of the technology. They are audio conferencing, audio graphic, video conferencing, web based conferencing and computer conferencing and computer conferencing.

Audio Conferencing: This involves the live (real-time), exchange of voice messages over telephone not work when low bind width text and still images such as graph diagrams or fixtures can also be exchanged along with voice messages. Non Moving visuals are added using computer keyboard or by drawing/writing on a graphic tablet or white board.

Audio Graphic: Audio graphic teleconferencing system involves the use of computer or fasiurile technology to transmit visuals to support audio some computer Systems allow the transmission or graphic, programs and data where each Site sees anything on the instructor computer seven besides hearing the audio graphic systems are good for classes that involve a lot of illustrations, Such as equations or computer applications.

Web based Conferecing: Web based conferencing involves the transmission of text and graphic, audio and visual via the internet, it required the use of a computer with a Brower and communication can be synchronous and asynchronous.

Computer Based Instruction: computer based instruction (CBI) refers to instructional program that the student uses alone on a personal computer, the program is usually On CD ROM, in multi-media format (graphic, text, sound and video). It Divides computer based instruction into multi media based like CDROM, E-mail and WWW.

Based Instruction: With the enormous number of resources available online, and the increasing number of people who have access to the internet, web-based instruction Considered one of the fastest media for teaching and learning. The world Wide web provides a cost effective, technology rich, and interactive Medium.

\section{Use Of Instructional Delivery Tools To Improve The Quality Of Education.}

Improving the quality of education and training is a critical issue, particularly at a time of university expansion. Instructional delivery tools Nzeaka, Iwu and Anaele (2012) serves as transformational tools which when use approximately can promote the shifts to learner centered environment through;

\section{Motivating to learn:}

Information and communication technology such as video, television, and multimedia computer software that combine text, sound and colorful moving images can be used to provide challenging and authentic content that will engage the student in the learning process. Litevactive radio likewise makes use of sound effect, songs, dramatization, comic skills and other performance conventions to prepare the students to listen and become involved in the lesson being delivered.

2. Facilitating the acquisition of basic skills:

The transmission of basic and concepts that are the information of higher order thinking skills and creativity can be facilitated by instructional tools through drill and practice. Instructional television programs helps students to master skills and content through repetition and reinforcement.

3. Enhancing teacher development capacity: Instructional delivery tool Is used to improve access to and the quality of teachers development. More courses are added to tertiary institutions which encourage reform.

4. Promote paradigmatic shift: Research has shown that the appropriate use of instructional delivery tool can catalyze the paradigmatic shift in both content and pedagogy that is at the heart of education reform in the 21st century. If designed adequately, it can promote the acquisition of the knowledge and skills that will empower students for life home learning. (Thij's 2002).

Challenges Of Instructional Delivery Tools In Tertiary Institutions.

Iwu And Ike (2018) stated the following as The challenges of instructional delivery tool in Tertary Institutions. 
1. The challenges of instructional delivery are both educational and administrative. The prominent among the administrative problems in cost. Over the years, the cost in purchasing most of the instructional tools has been on the high side. This has been a deterrent to the adoption of instructional tools for purposes in most universities.

2. The meager funding of education in Nigeria coupled with low technological level has been an impeachment to the provision of instructional delivery tools and use for instruction in Nigeria universities.

3. Death of trained personnel militates against the use of instructional deliver tools for instruction. Experts with technical know how of instructional tools are few.

4. Another impediment to the use of instructional delivery tools can be attributed to the syndrome of resistance to change among the Nigerian lecturers. They regard the use of instructional delivery as an increase in their tasks in the classroom without adequate compensation .

5. Closely related to resistance to change is the problem of poor technological development in Nigeria. Nigeria is a developing country where the rate of illiteracy and poverty is high among young and old.

\section{Discussion and Suggestions}

The world is global village. The present age of technological advancement has brought changes into virtually all human endeavor including teaching and learning process, acquisition of instructional delivery literacy skills as well as good face-value in computer education is a singqua-non for all and sundry especially lecturers and non academic staff in the universities, promotion in places of works and securing a well paid job are all attached to instructional delivery literacy hence the society should get more enlightened through instructional delivery tools. The under listed recommendations were put forward:

1. The parliamentarian should pass a bill on stabilizing the pride of computers in the market to make it easier for people to acquire at a reduced rate.

2. The government should provide enough funds for universities to purchase instructional delivery tools for instructional purposes and make available suitable environment in our tertiary institutions.

3. curriculum developers should make educational technology one of core and compulsory courses to be offered and passed in all the department in tertiary institutions

4. Conferences, workshop and symposium should be organized to train people and enlighten them on the need for instructional delivery tools in universities.

\section{REFERENCES}

Baron A. (1998) Designing web-based learning training. British journal of Educational Technology, 29 (4) 355371.

Collis B. (2002) Information Technologies for education and training. In Adelsberger H,(Eds), Handbook on Technologies for information and Training, Beerlin. Spinger.

Duffy .T. \& Euningham.B (2006). Constructivism, implications for the design and Harris, delivery of instructional. Handbook of research for educational telecommunication and technology 170-198.

Harris, T (1998). Learning with Technology using computers as cognitive tools. Jonassen (Ed), Handbook of Research Educational on Educational Communications and Technology (693-719) New York, Macmillan.

Iwu and Ike (2017). Why College teachers do not use ICT facilities in teaching. Learning, 2(3) , 41-50.

Littlejohn A, (2002). The amazing patient tutor; students interactions with an online Carbohydrate chemistry course. British Journal of Educational Technology, 33(3), 313-321.

Nzeako R.C (2010). The need of ICT in rural area centre for Africa. Development Conference held at University legion, Accra Ghana

Oliver R. (2000). Creating meaningful contexts for learning in web-based settings. Proceedings of open learning 2000 (pp 53-62) Bridane Learning Network, Queenland. 
Nwosu. B.O (2018). Information and communication technology in library services. Coal Journal of Technology 2(1).

Thij's A etal (2002). Learning through the web available online. http//www.decidentonl/publication. 